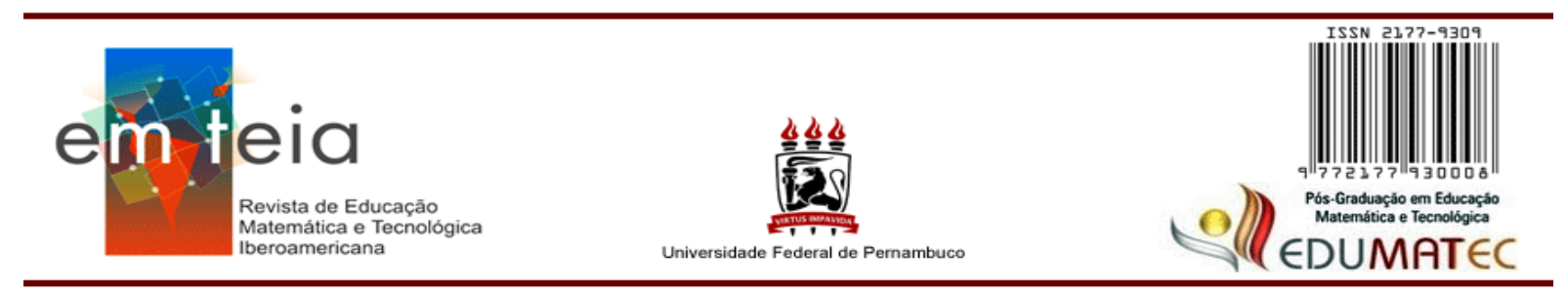

\title{
UMA REFLEXÃO DE TEXTOS ELABORADOS POR PROFESSORAS DA EDUCAÇÃO INFANTIL SOBRE EARLY ALGEBRA
}

\author{
A REFLECTION OF TEXTS DRAWN UP BY CHILDREN'S EDUCATION \\ TEACHERS ON EARL Y ALGEBRA
}

\author{
Ana Virginia de Almeida Luna \\ Universidade Estadual de Feira de Santana - BA - Brasil \\ avaluna@uefs.br \\ Vera Lucia Merlini \\ Universidade Estadual de Santa Cruz - BA - Brasil \\ vlmerlini@uesc.br
}

Vanessa Nascimento da Silva Colégio Despertar/NEEMFS - BA - Brasil vanessa-n-silva@hotmail.com

\section{Resumo}

Esta pesquisa tem como objetivo analisar quais textos do discurso da Álgebra as professoras da educação infantil reconhecem antes de iniciarem uma formação em Early Algebra ao elaborarem situações-problema para seus estudantes. Para tanto, foi desenvolvida uma pesquisa com abordagem qualitativa, por meio de análise documental. Esta coleta teve a participação de vinte e quatro professoras que lecionam na educação infantil, em duas creches e uma escola da rede pública do interior da Bahia. Foi solicitado que elas elaborassem seis situações-problema para seus estudantes envolvendo o conteúdo de Álgebra. Os dados foram coletados durante um dos módulos da formação de professores em Early Algebra. De um modo geral, os resultados indicam a importância do pensamento algébrico e do raciocínio aritmético serem desenvolvidos desde os anos iniciais do ensino fundamental, contemplando a educação infantil. Foi possível observar que os professores, ainda que de forma discreta, elaboraram textos legítimos referentes ao discurso algébrico.

Palavras- Chave: Early Algebra; Educação Infantil; Pensamento algébrico; Prática pedagógica.

\begin{abstract}
This research aims to analyze which algebra texts teachers of early childhood can recognize before starting a formation in Early Algebra at elaborating problematic situations for their students. For this, a research with qualitative approach was developed, through documentary analysis. This collect had the participation of 24 teachers of early childhood education, in two nurseries and one public school in the interior of Bahia. They were asked to elaborate six problematic situations for their students about algebra. Data were collected during one of the teacher's training modules in Early Algebra. In general, the results can determine the need and the importance of algebra and
\end{abstract}


arithmetic development since the first years of elementary school, that also can be applied to an early childhood education. It was possible to observe that teachers, even in a discreet way, can elaborate legitimate texts referring to algebraic discourse.

Keywords: Early Algebra; Kindergartners; Algebraic thinking; Pedagogical Practice.

\section{Introdução}

Frequentemente, os estudantes da educação infantil até os Anos Iniciais do Ensino Fundamental são apresentados à matemática por meio da aritmética, com foco em resolução de problemas envolvendo as quatro operações (LINS; GIMENEZ, 1997). Segundo esses autores, a introdução da álgebra só ocorre no início dos Anos Finais do Ensino Fundamental como algo desconectado dos outros conteúdos estudados. Os autores ainda destacam que tal escolha é uma questão de tradição no currículo escolar, uma vez que, segundo eles, se faz necessário o uso de conhecimentos prévios para que a álgebra seja incluída no currículo.

Esta é uma questão que vem sendo discutida entre pesquisadores da Educação Matemática (LUNA; SOUZA, 2013; FALCÃO, 2003; LINS; KAPUT, 2004; VALE; PIMENTEL, 2013; LUNA; SOUZA; SOUZA, 2015), com o intuito de chegar a um consenso acerca de qual seria o melhor momento para iniciar o estudo do pensamento algébrico. Em pesquisas realizadas por Lins e Kaput (2004), Blanton e Kaput (2005), Vale e Pimentel (2013) podemos observar que quanto mais cedo essa inserção ocorrer, mais os alunos terão a possibilidade de desenvolver estratégias que possam favorecer o desenvolvimento desse pensamento no decorrer da educação básica. Como apresenta Falcão (2003), a álgebra pode ser considerada um instrumento cultural no auxílio da resolução de problemas, motivo pelo qual o momento de sua apresentação pode e deve ser questionado. Na mesma linha argumentativa, Lins e Gimenez (1997) abordam que o ensino da álgebra, além de ter sua introdução antecipada, deverá ser desenvolvido de forma concomitante ao ensino da aritmética.

Desde a década de 1990, autores (LINS, 1992; THOMPSON, 1995; LINS; GIMENEZ, 1997) pesquisam sobre o desenvolvimento do pensamento algébrico, sendo que atualmente essas discussões têm ganhado legitimidade (CANAVARRO, 2007; BRANCO, 2008; CARRAHER; SCHLIEMANN; SCHWARTZ, 2008; CARRAHER; SCHLIEMANN, 2016; LUNA; SOUZA; BORTOLOTI, 2017; OLIVEIRA, 2018). Nos documentos oficiais, a exemplo da Base Nacional Comum Curricular (BNCC) (BRASIL, 2017), a Álgebra passa 
a fazer parte dos Anos Iniciais do Ensino Fundamental, entretanto as discussões sobre o pensamento algébrico ainda são incipientes.

Para que tal inserção ocorra o quanto antes, se faz necessária a formação continuada de professores que atuam nas salas de aula, buscando fazer a inclusão do ensino da álgebra nos currículos, com o intuito de desenvolver o pensamento algébrico dos alunos (BLANTON; KAPUT, 2005). Sendo assim, nesta pesquisa buscamos analisar o que professores da educação infantil reconhecem do conteúdo Álgebra antes de participarem de uma formação, ao elaborarem situações-problema para seus alunos.

Esse artigo se divide em cinco seções, sendo a primeira intitulada como "A prática pedagógica no contexto da educação infantil". Nela, apresentamos conceitos do quadro teórico do estudo com base em Bernstein (2000, 2003). Na segunda seção, "Ensino da álgebra na Educação Básica", abordamos uma análise dos documentos oficiais com relação ao ensino da Álgebra durante a Educação Básica. Na terceira seção, “O desenvolvimento do pensamento algébrico e a Early Algebra", trazemos conceitos relevantes do pensamento algébrico com seus tipos e formas de apresentação. Na quarta seção, "O contexto da pesquisa", expomos o instrumento utilizado na coleta de dados e os métodos utilizados na pesquisa. Na quinta seção, “Apresentação e análise dos dados”, apresentamos e analisamos os dados. Por fim, exibimos as considerações finais dessa pesquisa.

\section{A prática pedagógica no contexto da Educação Infantil}

Para que pudéssemos analisar as produções dos professores da Educação Infantil fizemos a opção de realizá-la à luz das ideias teóricas de Bernstein (2003). Desse modo, trouxemos alguns termos que julgamos necessários para nosso estudo, segundo a visão do referido autor.

Iniciamos com a prática pedagógica como as relações entre os envolvidos no processo que, para Bernstein (2003), é como um condutor cultural, uma forma social. No contexto em que estamos envolvidos, consideramos as relações estabelecidas entre professor e aluno, contudo, para esse mesmo autor, a prática pedagógica poderia acontecer também entre pais e filhos, médico e paciente.

Entendemos o texto, segundo Bernstein (2003), como qualquer forma de comunicação produzida por uma pessoa, seja ela falada, escrita, visual, espacial, expressa na postura ou na vestimenta. Deste modo, qualquer forma de comunicação feita pelo 
professor ou pelo aluno é considerada texto, contudo, tal conceito só será considerado como legítimo quando pudermos encontrar um significado entre ele e o contexto de sua produção.

Partindo do pressuposto que o contexto é uma formação de professores, a prática pedagógica envolve a relação entre formadores e professores da Educação Infantil. Para Bernstein (2000), os agentes são os formadores e professores; as diferentes áreas de conhecimento, que podem ser matemática, história, geografia, são consideradas como categorias. Essas relações, por sua vez, ocorrem entre e dentro dessas categorias, geram princípios para regular as práticas, os quais se intitulam como classificação e enquadramento.

Uma maneira de entender o funcionamento interno dessa prática é fazer uma análise do discurso pedagógico. De acordo com Bernstein (2000), o discurso pedagógico é um princípio de apropriação de outros discursos regulativo instrucional de forma mútua, com o intuito de proporcionar, a partir de uma realização, a condução e aprendizagem de diferentes conteúdos quando falamos em sala de aula. Ainda de acordo com o autor, essas modalidades do discurso caracterizam os textos legítimos dentro do discurso pedagógico, sendo que o discurso regulativo se refere à forma como é construída uma ordem, relação, norma, comportamento e identidade social. O discurso instrucional, por sua vez, transmite as competências especializadas e sua mútua relação, em nosso contexto, seria o texto do discurso algébrico. O discurso regulativo é dominante em relação ao discurso instrucional, pois as mensagens sobre o que constitui conhecimento legítimo estão sempre contidas nas mensagens sobre o que se constitui como comportamento apropriado em um determinado contexto (BERNSTEIN, 2003; LUNA, 2012).

Dentro de um espaço de formação (contexto), a classificação, segundo Bernstein (2000), ocorre por meio das relações entre as categorias agentes (formadores e professores) e as diferentes áreas de conhecimento (Matemática, História, Geografia etc.), que estão ligadas às regras de realização, do que pode ser dito dentro do contexto, as relações de poder que compõem as formas de interação. $\mathrm{O}$ enquadramento intercorre por meio das relações dentro de um contexto (formação continuada), assim temos a relação entre quem conduz (formador) e quem desenvolve (professores da educação infantil) o conteúdo. Para que essa relação aconteça os professores se apropriam do texto legítimo, regras de reconhecimento, que aqui são as relações de controle que compõem as formas de interação. É a partir dessas regras de realização e de reconhecimento que possibilitam a criação do texto legítimo (LUNA, 2012). 
A partir dos termos expostos, iremos analisar que textos do discurso algébrico as professoras da Educação Infantil reconhecem ao elaborarem situações-problema para seus estudantes. Assim apresentaremos na próxima seção como decorre o ensino de Álgebra a partir dos documentos oficiais.

\section{Ensino da Álgebra na Educação Básica}

Abordamos aqui documentos oficiais de publicação nacional e internacional, que poderão nos orientar na realização de uma reflexão dos currículos escolares, com o intuito de observar o que se revela acerca de Álgebra como conteúdo curricular.

Iniciamos a análise pelos Parâmetros Curriculares Nacionais (PCN) (BRASIL, 1997, 1998b) que constituem as propostas de orientação para a elaboração de currículos para os atuais Anos Iniciais (anteriormente chamados de $1^{\circ}$ e $2^{\circ}$ ciclos) e Anos Finais (anteriormente chamados de $3^{\circ}$ e $4^{\circ}$ ciclos) do Ensino Fundamental, respectivamente.

Além desses documentos que mencionamos, no final da década de 1990 foi publicado o Referencial Curricular Nacional da Educação Infantil (RCNEI) (BRASIL, 1998a), que teve como objetivo colaborar nas condutas escolares perpassando pelo planejamento, desenvolvimento e avaliação, atendendo às necessidades das crianças na Educação Infantil.

Ao analisarmos esses documentos não encontramos nenhuma menção à Álgebra no Referencial Curricular Nacional da Educação Infantil (BRASIL, 1998a). Quanto aos PCN (BRASIL, 1997), encontramos, de forma sutil, a possibilidade de se desenvolver com os estudantes uma pré-álgebra, mas sem especificar tal proposta. Consequentemente, não está explícito que o professor necessite desenvolver com seus alunos conteúdos nos quais faça referência ao ensino da álgebra.

Analisando especificamente os PCN (BRASIL, 1998b, p. 84), é possível perceber que o documento orienta que, já no terceiro ciclo (atuais $6^{\circ}$ e $7^{\circ}$ anos), o ensino de Matemática vise ao desenvolvimento do pensamento algébrico a partir da exploração de situações de aprendizagem, quando "as noções algébricas são exploradas por meio de jogos, generalizações e representações matemáticas (como gráficos, modelos)" (BRASIL, 1998b, p. 84). Além disso, o mesmo deixa implícito que, no início, o desenvolvimento do pensamento algébrico deve ser repensado com o propósito dos alunos conseguirem diferenciar as diversas funções que tem a álgebra, além de propiciar atividades que estejam 
inter-relacionadas com as diferentes concepções da Álgebra e não somente realizar operações de forma mecanizada. Todavia, deixa explícito que o estudo de álgebra será realmente aprofundado nos Anos Finais do Ensino Fundamental.

Esses documentos nos mostram que as práticas de ensino são responsáveis por oferecer subsídios para que os alunos ampliem seus conhecimentos acerca do discurso entre a Aritmética e a Álgebra, construindo as relações necessárias para que não ocorra um distanciamento entre os Anos Iniciais e os Anos Finais. Atualmente, os alunos iniciam os estudos em Matemática com Aritmética, que intercorre por meio de cálculos numéricos apoiando-se nas quatro operações, deixando para os Anos Finais a apresentação da Álgebra. Esta é apresentada em forma de equações, fazendo uso de letras do alfabeto com valor desconhecido, necessitando de manipulações para que o valor das mesmas seja encontrado (LUNA; SOUZA, 2013).

O National Council of Teachers of Mathematics (NCTM, 2007), documento do Conselho Nacional dos Estados Unidos da América, considera a Álgebra como um fio condutor curricular, sendo que esta deve percorrer toda a educação básica, desde a Educação Infantil até o Ensino Médio. Tal documento oferece orientações de como é possível ter uma proposta curricular que seja contínua quando se analisa a Álgebra enquanto componente curricular, além de apresentar normas e objetivos diferenciados para cada nível de escolaridade, propondo uma integração entre a aritmética e álgebra por meio de processos graduais.

As normas propostas pelo NCTM (2007) perpassam pela compreensão de padrões, relações e funções; representação e análise de situações e estruturas matemáticas usando símbolos algébricos; utilização de modelos matemáticos para representar e compreender relações quantitativas; e análise da variação em diversos contextos da Educação Infantil até o Ensino Médio.

Luna e Souza (2013) e Kieran (2004) concordam com o NCTM (2007), quando esse se refere ao estudo da álgebra como algo que deverá ser entendido como um fio condutor, que perpassa desde a educação infantil e que continue por toda a educação básica. Trabalhos como os de Thompson (1995), Lins (1992) e Lins e Gimenez (1997) começaram a ser divulgados e estudados em nosso país já a partir da década de 1990. Na primeira década do século XXI foi cunhado o termo Early Algebra (KATZ, 2007) que traduz, se assim podemos nos referir, o desenvolvimento do pensamento algébrico dos alunos já nos Anos Iniciais de escolaridade. 
As orientações para o ensino da Álgebra e do desenvolvimento do pensamento algébrico no Brasil, com relação aos documentos oficiais, ainda são recentes. Elas foram implementadas com a publicação dos elementos conceituais e metodológicos para a definição dos direitos de aprendizagem e desenvolvimento do ciclo de alfabetização $\left(1^{\circ}, 2^{\circ}\right.$ e $3^{\circ}$ anos) do Ensino Fundamental (BRASIL, 2012), proposto pelo Ministério da Educação (MEC), que teve como objetivo expressar os conteúdos básicos, relevantes, necessários e com significado social.

Nesse documento, o pensamento algébrico é apresentado como um eixo estruturante que auxiliaria os estudantes a compreenderem padrões e relações a partir de diferentes contextos. Para que tal feito seja possível, é necessário que seja assegurado aos estudantes a alfabetização e o letramento matemático, para que possam compreender, reconhecer e produzir padrões, estabelecer critérios para agrupar, classificar e ordenar objetos.

Atualmente no Brasil temos a BNCC (BRASIL, 2017), instituída na segunda década do presente século, que normatiza os direitos de aprendizagem, além de garantir que o desenvolvimento dos estudantes seja assegurado no decorrer da educação básica, abrangendo desde a Educação Infantil até o Ensino Médio. Esse documento apresenta a Unidade Temática de Álgebra desde os Anos Iniciais, trazendo ideias de regularidade, generalização de padrões e propriedades da igualdade e a necessidade que intercorra uma relação entre as unidades temáticas, tal como a de fazer uma relação entre a Aritmética e Álgebra. Cabe salientar que esse documento se restringe aos Anos Iniciais e Finais, não se reportando à Educação Infantil a respeito do desenvolvimento do pensamento algébrico.

Com a análise desses documentos, podemos perceber que a álgebra vai além do ensino de técnicas de manipulação de símbolos, o que significa que os estudantes precisam compreender conceitos algébricos. Além disso, também é possível perceber que a inserção do desenvolvimento do pensamento algébrico é benéfico desde que aconteça desde a Educação Infantil, perpassando por toda Educação Básica. Pela relevância da temática, continuaremos nossas reflexões diante do tema, apresentando possíveis discussões sobre como poderá ocorrer a relação entre a Aritmética e Álgebra.

\section{Desenvolvimento do pensamento algébrico e a Early Algebra}

A literatura nacional e a internacional têm colocado como ponto de pauta questões relacionadas a como desenvolver o pensamento algébrico em crianças do Ensino 
Fundamental, em especial dos Anos Iniciais (LINS, 1992; LINS; GIMENEZ, 1997; FALCÃO, 2003; KIERAN, 2004; BLANTON; KAPUT, 2005; PONTE; BRANCO; MATOS, 2009; CYRINO; OLIVEIRA, 2011; CARRAHER; SCHLIEMANN, 2016). Não há consenso em relação ao uso do termo pensamento algébrico. Deste modo, apresentamos perspectivas de alguns autores de como eles descrevem o pensamento algébrico.

Para Lins e Gimenez (1997), pensamento algébrico é uma maneira de elaborar conceitos para a álgebra. Esses autores levantam três pensamentos essenciais que o compõem, sendo eles: pensar aritmeticamente (trabalhar com números e operações aritméticas), pensar internamente (considerar os números e as operações a partir de suas propriedades) e pensar analiticamente (manipular com números desconhecidos como se fossem conhecidos). Segundo eles, os alunos desenvolvem a capacidade de pensar algebricamente ao produzir significados para os objetos algébricos, como o sinal da igualdade em equações, a regularidade em operações aritméticas como a propriedade comutativa da adição, por exemplo.

Para Ponte, Branco e Matos (2009), o desenvolvimento do pensamento algébrico é o maior objetivo do estudo da álgebra durante toda educação básica, não se limitando a manipulações de símbolos. O pensamento algébrico, na visão desses autores, está além dos objetos de estudo: caminham sobre o modo como são estabelecidas relações entre esses objetos. Destacam-se três vertentes: representar, raciocinar e resolver problemas. A primeira delas está relacionada à capacidade do aluno fazer uso de diversos sistemas de representação; a segunda vertente, raciocinar, de forma dedutiva e indutiva, tem o intuito de relacionar, por exemplo, analisando as propriedades de objetos matemáticos; a terceira e última vertente, generalizar, ao estabelecer relações válidas para uma certa classe de objetos matemáticos.

Blanton e Kaput (2005) propõem o início do desenvolvimento do pensamento algébrico como um processo em que os alunos generalizam as ideias matemáticas a partir de casos particulares. Essas generalizações, por sua vez, estão baseadas em um discurso algébrico que se torna cada vez mais formalizado em conformidade com a experiência e idade de cada aluno. Esses autores classificam esse pensamento em quatro formas: aritmética generalizada, pensamento funcional, modelação e equações.

Os autores citados comungam de ideias semelhantes a respeito do pensamento algébrico, apresentando como características comum a possibilidade de generalizar e de encontrar resultados por meio das relações, defendendo o desenvolvimento do pensamento 
algébrico desde os Anos Iniciais, fazem-se necessários estudos voltados para o discurso algébrico.

Carraher, Schliemann e Schwartz (2008) também argumentam que a Álgebra no Ensino Fundamental, denominada por eles como Early Algebra, não deve se restringir apenas à aquisição de códigos algorítmicos ao final desta etapa de ensino. Eles destacam que as noções de função e incógnita poderiam ser mais bem desenvolvidas se estes assuntos fossem abordados com maior frequência e desde o Ciclo de Alfabetização.

Assim, tomaremos como definição do pensamento algébrico a forma de se estabelecer relações entre objetos e generalizá-los, bem como resolver situações-problema das mais variadas formas (LUNA; SOUZA; BORTOLOTI, 2017). Luna e Souza (2013) apontam que, na maioria das vezes, não se estabelece uma relação entre a aritmética e álgebra e esta ruptura provoca dificuldades no desenvolvimento do pensamento algébrico. As autoras sinalizam a importância desta relação, advertindo que "é fundamental que o professor apresente a passagem da aritmética à álgebra como continuidade e não como ruptura" (LUNA; SOUZA, 2013, p. 825).

Com base nos estudos voltados à Early Algebra e pensamento algébrico, apresentamos quatro vertentes: símbolos, sequência, relação funcional e equivalência. Cabe ressaltar que elas serão exploradas durante o processo de formação de professores. Apresentamos, portanto, nesta seção algumas discussões importantes para fundamentação desse trabalho.

\section{Símbolos}

A abordagem da vertente símbolo em sala de aula é relevante para que os alunos desenvolvam a possibilidade de representar, interpretar e reconhecer símbolos em diferentes contextos. Trouxemos para essa discussão três autores nos quais nos apoiamos.

Segundo Branco (2008), os alunos apresentam dificuldades em lidar com equações quando as letras se juntam aos números. Para a autora, essa dificuldade está atrelada à não compreensão do significado dos símbolos. A linguagem formal, que é própria da Álgebra, acrescida de todas as suas regras e procedimentos, é distinta se compararmos ao trabalho realizado, no âmbito da Aritmética, desde os primeiros anos de escolaridade.

Ribeiro (2010) considera os símbolos como uma forma de representação de um objeto, o que os torna diferentes da reprodução pois, ao reproduzirmos um objeto, pressupõe 
algo muito parecido, enquanto o símbolo traz uma percepção daquele objeto a ser representado.

De acordo com Arcavi (2006), na Aritmética temos os estudos voltados para o desenvolvimento do sentido do número. Ainda para o autor, a mesma concepção pode ser aplicada com a Álgebra, que tem como um dos seus objetivos contribuir para o desenvolvimento do sentido dos símbolos. Portanto, faz-se necessária a compreensão de diferentes componentes que os envolvem, sendo eles:

(i) compreensão dos símbolos (quando e como podem e devem ser usados para exibir relações, generalizações e demonstrações) e sentido estético do seu poder; (ii) capacidade tanto de manipular como de ler através de expressões simbólicas; (iii) consciência que é possível exprimir informação dada ou desejada através de relações simbólicas; (iv) capacidade de selecionar uma representação simbólica e de melhorá-la se necessário; (v) consciência da necessidade de rever os significados dos símbolos durante a realização de uma tarefa, tendo em conta a nossa intuição e o contexto do problema; (vi) consciência que os símbolos podem desempenhar diferentes papéis em diferentes contextos. (ARCAVI, 2006, p. 2-4)

Diante desses componentes citados por Arcavi (2006), entendemos que os estudantes necessitam de várias experiências de forma contínua para que o desenvolvimento do pensamento algébrico seja construído durante toda a Educação Básica. Para ilustrar o que foi relatado acerca dos símbolos, apresentaremos uma imagem que remete a significados possíveis de serem reconhecidos já na Educação Infantil.

Figura 2 - Exemplo de Símbolos

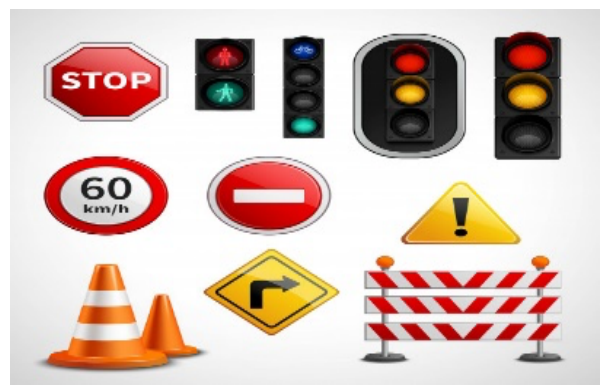

Fonte: <a href="https://br.freepik.com/fotos-vetores-gratis/bandeira">

Bandeira vetor criado por macrovector - br.freepik.com $</ a>$

Os sinais de trânsito são úteis para desenvolver com as crianças o sentido dos símbolos, pois eles estão presentes no nosso dia a dia. O fato de fazer parte do cotidiano auxilia o professor no desenvolvimento de atividades em que seja necessário fazer o reconhecimento de imagens como essa, interpretá-las e representá-las. 


\section{Sequências}

A sequência é aqui entendida como um objeto matemático importante na identificação de regularidades e padrões, o que auxilia o processo de generalização (PONTE; BRANCO; MATOS, 2009). A generalização de padrões é um meio que viabiliza o desenvolvimento do pensamento algébrico. A partir dos padrões visuais e figurativos, o estudante pode compreender e dar sentido às expressões numéricas, o que possibilitará a apropriação de uma linguagem algébrica mais formal (VALE et al., 2011).

De acordo com o NCTM (2007), o trabalho com padrões e sequências pode constituir uma base para a compreensão do conceito de função, podendo ter início desde os primeiros anos da escolaridade, fazendo uso da linguagem natural para identificar relações e representar as generalizações. No âmbito da Matemática, ao pensarmos em sequência, é comum imaginarmos tal conceito como um conjunto de números colocados em uma determinada ordem, porém, não há somente essa opção de construção. Entendemos sequência, por outro lado, como um conjunto de elementos, e não apenas de números, organizados em uma determinada ordem.

Segundo Ponte, Branco e Matos (2009), temos duas formas de representar as sequências: em forma de ícones ou de números. Os estudantes iniciam descrevendo as regularidades que são postas nessas sequências verbalmente. Quando levamos em consideração a ordem das sequências, observamos que elas podem ser: repetitivas, recursivas, crescentes ou decrescentes.

$\mathrm{Na}$ sequência repetitiva podemos perceber que há uma alternância entre os elementos sempre se repetindo, ou seja, eles são apresentados de forma cíclica. Tais elementos podem ser apresentados das duas formas.

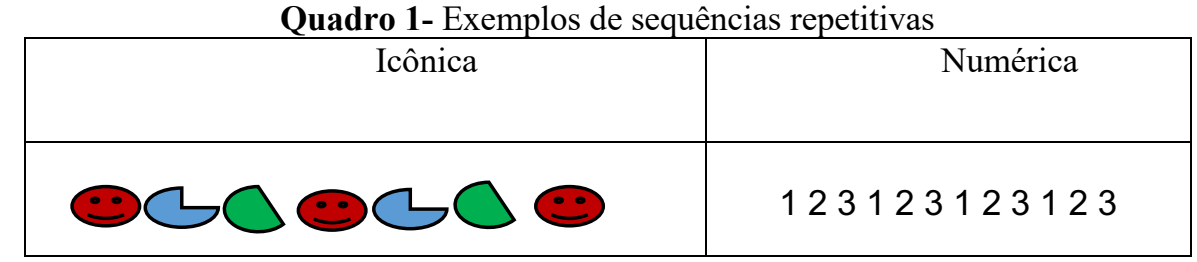

Fonte: As autoras.

As sequências crescentes ou decrescentes também podem ser apresentadas de forma icônica ou numérica, como mostramos nos exemplos a seguir. 
Quadro 2- Exemplos de sequências crescentes

\begin{tabular}{|c|c|}
\hline Icônica & Numérica \\
\hline \multirow{2}{*}{ I } & 1212212221222 \\
\hline
\end{tabular}

Fonte: As autoras.

Esses dois exemplos, representados nas duas formas, icônica e numérica, estão relacionados a uma sequência crescente. Eles apresentam dois elementos, um deles se repete de modo constante e o outro aumenta uma unidade a cada repetição.

\section{Relação funcional}

Podemos definir relação funcional como a capacidade de estabelecer relações entre grandezas. Segundo Blanton (2008), uma função seria uma forma de demonstrar a regularidade que existe entre a variação com relação a essas grandezas.

Blanton e Kaput (2005) se baseiam em outros referenciais para apontar três tipos desta relação, sendo elas: regularidade recursiva, pensamento de covariação e relação de correspondência. Abaixo segue um exemplo que ilustrar como cada tipo é abordado:

Quadro 3 - Exemplo de relação funcional

\begin{tabular}{|c|c|}
\hline Qtde de carros & Qtde de pneus \\
\hline 1 & 4 \\
2 & 8 \\
3 & 12 \\
4 & $?$ \\
\hline
\end{tabular}

Fonte: As autoras.

Temos uma regularidade recursiva quando identificamos uma variação em uma determinada sequência de valores. Isso é possível de ser observado na variação da sequência da quantidade de pneus, apresentado no Quadro 3, que demonstra que sempre teremos a quantidade anterior adicionando quatro unidades.

O pensamento de covariação está presente na análise da variação das duas grandezas simultaneamente; neste caso, a quantidade de carros aumenta de 1 em 1 , enquanto a quantidade de pneus aumenta de 4 em 4 . Por fim, temos a relação de correspondência, onde analisamos a relação entre as duas variáveis, sendo elas carros e pneus que, neste caso, apresenta uma variação de quatro vezes mais. 


\section{Equivalência}

Entendemos equivalência, a partir dos estudos com equações nos quais há diferentes formas de representação e não somente como um resultado determinado.

Para Ponte, Branco e Matos (2009), os alunos devem entender o sentido do sinal de igualdade, reconhecendo formas diferenciadas de representar o mesmo número, sem necessitar partir da definição de imediato. Os autores apresentam três significados que o sinal de igualdade pode assumir, sendo eles: como resultado de uma operação, sendo esse o mais utilizado durante os Anos Iniciais; como sinal de equivalência, quando houver igualdade entre os dois termos; e como uma relação funcional, quando há uma relação de dependência entre os dois lados da igualdade.

\begin{tabular}{|c|c|}
\hline \multicolumn{2}{|c|}{ Quadro 4 - Exemplo de equivalência } \\
\hline $4+6=3+7$ & $8-5=-4$ \\
\hline $7=2+5=3+4$ & $3+\ldots=9$ \\
\hline
\end{tabular}

Fonte: As autoras.

A seguir, apresentaremos o contexto da pesquisa, além do instrumento utilizado na coleta de dados e o método utilizado na pesquisa

\section{Metodologia}

Este artigo tem o objetivo de analisar quais textos do discurso da álgebra as professoras da educação infantil reconhecem antes de iniciarem uma formação em Early Algebra ao elaborarem situações-problema para seus estudantes. Cabe salientar que se trata de um recorte do projeto de pesquisa intitulado "A Early Algebra no Ensino Fundamental: mapeamento, diagnóstico e formação", financiado pela Universidade Estadual de Santa Cruz (UESC), CONSEPE: 2240454 115/17, com a coordenação interinstitucional da Prof ${ }^{a}$ Dr $^{a}$ Vera Merlini e a coordenação local da $\operatorname{Prof}^{\mathrm{a}} \operatorname{Dr}^{\mathrm{a}}$ Ana Virginia Luna, aprovado pelo CONSEPE, UEFS 048/2019, que tem como propósito fazer um mapeamento de pesquisas nacionais, aplicação de um diagnóstico analisando competências, concepções e estratégias com o intuito de oferecer uma formação para os professores envolvidos no projeto.

Ele foi desenvolvido com professores e alunos de três instituições municipais, sendo duas creches e uma escola, do interior da Bahia, que foram convidados a participar de todo 
o processo desse projeto que foi dividido em oito módulos. A escola em questão atende crianças do grupo 4 (quatro) ao nono ano dos Anos Finais do Ensino Fundamental, no entanto estão participando da pesquisa apenas a Educação Infantil e os Anos Iniciais do Ensino Fundamental. Nas creches são atendidas crianças de 2 (dois) a 5 (cinco) anos.

No módulo zero da estrutura investigativa desta pesquisa, as seguintes etapas foram seguidas para melhor desenvolvimento da coleta e análise dos dados: o convite para as escolas; as visitas dos pesquisadores que fazem parte deste estudo, os membros do Grupo de Pesquisa Núcleo de Estudos em Educação Matemática de Feira de Santana (NEEMFS); a apresentação e a coleta de dados iniciais com professores e alunos. A partir do módulo um, aconteceram encontros presenciais e online, onde foram discutidos tópicos relevantes ao estudo sobre o desenvolvimento do pensamento algébrico.

Para o presente estudo, foram utilizados os dados coletados no módulos zero, e para tanto, foi solicitado que as professoras elaborassem seis situações-problema para seus estudantes envolvendo o conteúdo álgebra, sem auxílio de qualquer material. Trinta e duas professoras elaboraram as situações-problema solicitadas, porém foram analisados somente os textos referentes às 24 professoras da educação infantil, envolvendo conceitos algébricos, totalizando 144 situações-problema. Dessas, foram analisadas de fato 128 situaçõesproblema, já que 16 foram deixadas em branco.

Para viabilizar essa pesquisa foi utilizada a análise documental que, de acordo com Alves-Mazzotti (2002), pode basear-se em quaisquer registros e, portanto, pode ser utilizado como fontes de informação, uma vez que, para o desenvolvimento de uma pesquisa, todo registro é considerado um documento.

Na seção seguinte, apresentaremos e discutiremos os dados da pesquisa.

\section{Apresentação e análise dos resultados}

Nesta seção analisamos e discutimos os dados coletados no módulo zero. Cabe ressaltar que a produção desse material pelas professoras aconteceu antes de iniciar a formação, como fora apresentado na seção anterior.

A partir dos dados coletados, classificamos os textos produzidos e apontamos quatro tipos de categorias. O quadro 5 apresenta tais categorias. 
Quadro 5 - Categorias dos textos referentes aos tipos utilizados

\begin{tabular}{|c|l|}
\hline Categoria & Tipos \\
\hline C1 & Álgebra \\
\hline C2 & Aritmética \\
\hline C3 & Pensamento algébrico \\
\hline C4 & Não legitimado \\
\hline
\end{tabular}

Fonte: As autoras e os membros do NEEMFS.

Cabe ressaltar que, além de elencarmos as categorias $(\mathrm{C} 1, \mathrm{C} 2, \mathrm{C} 3$ e $\mathrm{C} 4)$, sentimos a necessidade de criar subcategorias, que ora apresentamos. Partindo dos dados que tínhamos, para a "C1 Álgebra" destacamos duas subcategorias, sendo elas: símbolo e sequência. Para “C2 Aritmética” foram três subcategorias: classificação, contagem e agrupamento, além de estrutura aditiva e estrutura multiplicativa. Já na categoria “C3 Pensamento Algébrico", há uma subcategoria: com intervenção. Por fim, para a categoria "C4 Texto não legítimo", temos três subcategorias: inconsistente, incompleto e inapropriado para Educação Infantil.

Salientamos que essas subcategorias foram devidamente detalhadas após a apresentação da Tabela 1, que traz a incidência de cada uma delas.

Tabela 1: Relação entre os textos e as categorias

\begin{tabular}{c|c|c|c|c|c|c|c|c|c}
\hline \multirow{2}{*}{ Cat } & \multicolumn{2}{|c|}{$\begin{array}{c}\text { C1 } \\
\text { Álgebra }\end{array}$} & \multicolumn{3}{c|}{$\begin{array}{c}\text { C2 } \\
\text { Aritmética }\end{array}$} & $\begin{array}{c}\text { C3 } \\
\text { Pensamento } \\
\text { Algébrico }\end{array}$ & \multicolumn{3}{c}{$\begin{array}{c}\text { C4 } \\
\text { Texto não legítimo }\end{array}$} \\
\hline $\begin{array}{l}\text { Sub } \\
\text { cat }\end{array}$ & Símb & Sequ & $\begin{array}{c}\text { Clas/Cont/ } \\
\text { Agr }\end{array}$ & Adit & Mult & Com interv & Incons & $\begin{array}{c}\text { In- } \\
\text { comp }\end{array}$ & Inapr \\
\hline $\begin{array}{c}\text { Qtde } \\
(\%)\end{array}$ & 2 & 6 & 19 & 46 & 20 & 10 & 12 & 10 & 3 \\
$(1,6 \%)$ & $(4,7 \%)$ & $(14,8 \%)$ & $(36 \%)$ & $(15,6 \%)$ & $(7,8 \%)$ & $(9,4 \%)$ & $(7,8 \%)$ & $(2,3 \%)$ \\
\hline $\begin{array}{c}\text { Total } \\
(\%)\end{array}$ & \multicolumn{2}{|c|}{\begin{tabular}{c}
$(6,3 \%)$ \\
\hline
\end{tabular}} & \multicolumn{3}{|c|}{$\begin{array}{c}85 \\
(66,4 \%)\end{array}$} & $\begin{array}{c}10 \\
(7,8 \%)\end{array}$ & \multicolumn{2}{|c|}{$\mathbf{( 1 9 , 5 \% )}$} \\
\hline
\end{tabular}

Fonte: Dados da pesquisa

De posse dos dados da Tabela 1, podemos destacar alguns pontos relevantes. O primeiro deles nos remete à quantidade de situações-problema elaboradas no âmbito da aritmética. Se observarmos, tivemos um total de $66,4 \%$ de problemas classificados como tal, com ênfase na estrutura aditiva. Esses resultados corroboram o que os documentos oficiais indicam como ênfase na Aritmética (BRASIL, 1997; 1998a). Oficialmente, de fato, não era orientado o trabalho com a Álgebra para os Anos Iniciais do Ensino Fundamental, o que só ocorreu a partir de 2012 com a implementação dos elementos conceituais e metodológicos para a definição dos direitos de aprendizagem e desenvolvimento do ciclo de alfabetização (BRASIL, 2012). Enfatizamos que até hoje, para a Educação Infantil, os documentos oficiais não orientam ações para o desenvolvimento do pensamento algébrico (BRASIL, 2017). 
Outro aspecto a ser considerado é que, apesar de termos a categoria texto não legítimo, essa foi contemplada com a minoria das situações-problema, não ultrapassando a faixa dos 19,5\%. Para essa categoria, é preciso considerarmos que algumas das situaçõesproblema tidas como inconsistentes e incompletas no registro escrito poderiam ter outra conotação na oralidade dentro da sala de aula, tornando-se assim uma situação-problema legítima. Ao apresentar a "C4 Texto não legítimo", em especial na subcategoria incompleta, apresentamos um exemplo que elucida essa possibilidade de legitimar essa situaçãoproblema.

Um terceiro aspecto que destacamos é o fato de que, ainda que seja tímida a quantidade de situações-problema que remetem à álgebra $(6,3 \%)$, já há um indicativo de que as docentes apresentam uma aproximação com o pensamento algébrico, mesmo de forma intuitiva. Para comprovar a hipótese, essa pesquisa apresenta agora a análise de cada categoria e, também, de suas respectivas subcategorias.

Sobre a categoria C1 - Álgebra, é possível afirmar que essa se refere ao texto produzido pela professora em que foi possível identificar a mobilização do pensamento algébrico, como abordamos na seção quatro, a partir das quatro vertentes, a saber: símbolo, sequência, equivalência e relação funcional.

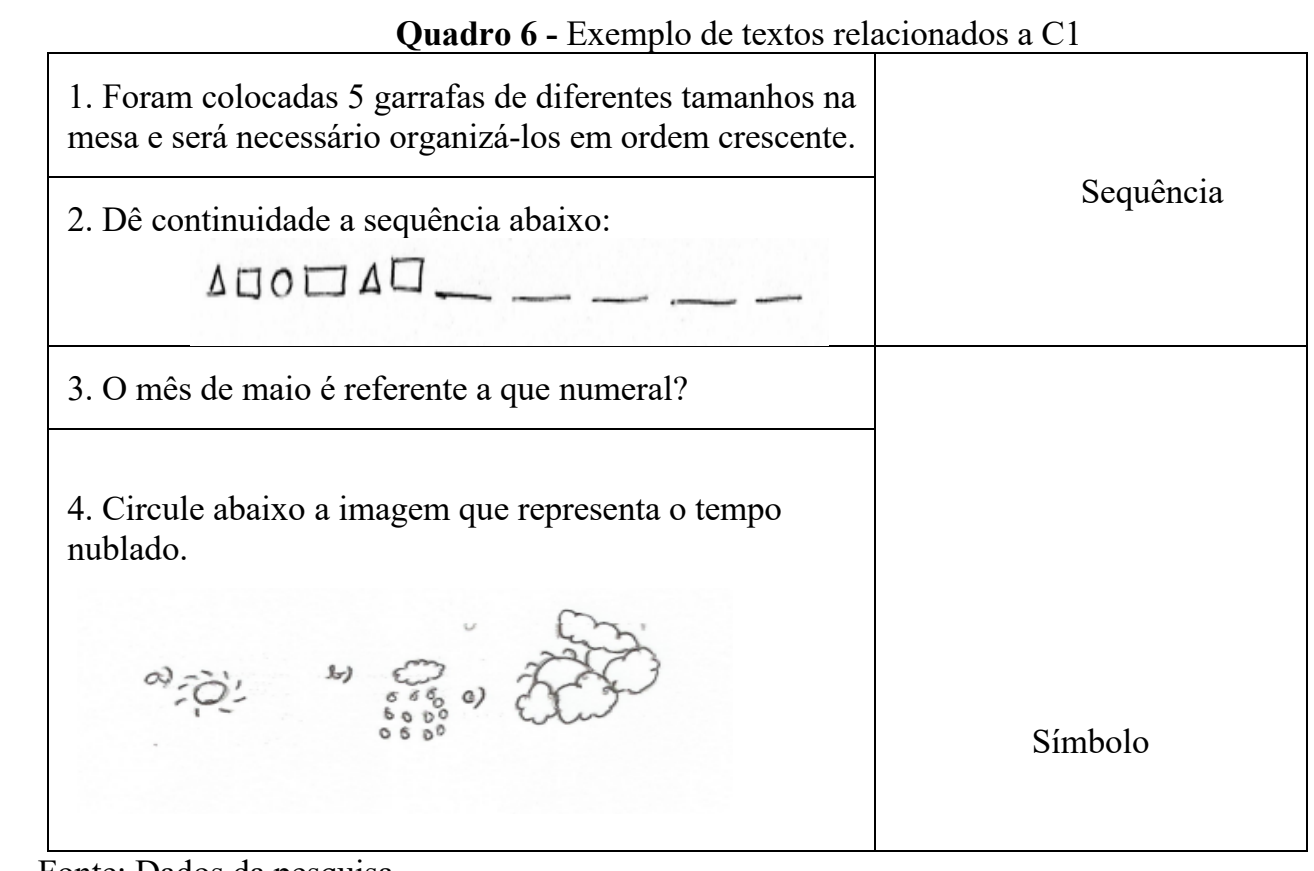

Fonte: Dados da pesquisa.

Nos textos elaborados pelas professoras relacionados a essa categoria C1, identificamos situações-problema envolvendo sequência e símbolo, conforme apresentados no Quadro 6. 
A situação-problema 1 referente à sequência, há uma situação na qual é necessário organizar as garrafas por tamanho na ordem crescente, ou seja, da menor para a maior. A situação-problema 2 trata-se de uma sequência repetitiva completa, na qual os alunos devem completar os espaços, dando continuidade com as figuras apresentadas. Conforme o NCTM (2007), a sequência é entendida como um conjunto de elementos organizados em uma determinada ordem, que pode ser crescente ou decrescente, como está proposta na situaçãoproblema 1. Além disso, Ponte, Branco e Matos (2009) observam que as sequências podem ser repetitivas, como na situação-problema 2, cujo grupo que se repete tem dois elementos, sendo esses o triângulo e o quadrado.

No que se refere às situações-problema 3 e 4, sendo estas aquelas que envolvem símbolos, uma está relacionada à linguagem natural e a outra à representação pictórica. A situação-problema 3 diz respeito ao símbolo numérico "5" referente ao mês de maio, ou seja, o quinto mês do ano. Ainda nessa categoria, temos a situação-problema 4, correspondente a símbolos, na qual se faz necessário que os estudantes reconheçam diferentes formas de representações relativas ao tempo. Assim como na aritmética, os símbolos são relevantes para a álgebra. De acordo com Arcavi (2006), é importante a compreensão de que os símbolos cumprem diferentes papéis em diversas situações, inclusive em seu cotidiano, daí a relevância do reconhecimento dos sentidos dos símbolos pelos estudantes desde o início da escolaridade.

Nesta categoria $\mathrm{C}$, podemos analisar que, mesmo timidamente, as situaçõesproblema envolvendo a Early Algebra estão começando a ser desenvolvidas por professoras da educação infantil. Ainda que haja quatro vertentes, durante a análise das situaçõesproblema, não identificamos na produção das professoras textos referentes à relação funcional e à equivalência.

Já na categoria "C2 - Aritmética", é possível afirmar que essa se refere ao texto produzido pelo professor em que observamos as situações-problema relacionadas com a contagem, classificação, agrupamentos, estrutura aditiva e estrutura multiplicativa.

Quadro 7 - Exemplo de textos relacionados a C2

1. Fazer contagem de meninos e meninas e fazer o registro. Depois fazer a contagem do total de alunos.

Contagem

2. Brincando de supermercado, Maria foi comprar um salgadinho que custava $\mathrm{R} \$ 3,00$, só que na hora de pagar Maria só tinha $\mathrm{R} \$ 5,00$. Quanto vamos precisar dar de troco para Maria?

Estrutura aditiva 


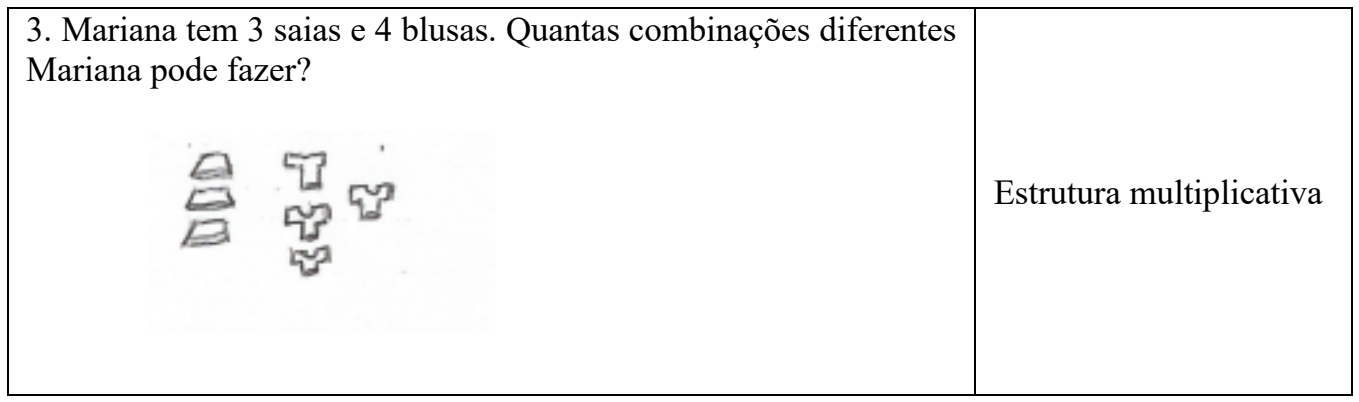

Fonte: Dados da pesquisa.

Nesta categoria C2, os textos elaborados pelas professoras têm seu foco na aritmética, sendo que o primeiro refere-se a uma típica situação-problema de contagem, pedindo a denominação da série numérica oral e em seguida o registro escrito. A segunda situação-problema está voltada para estrutura aditiva que, segundo os estudos de Santana (2012), está relacionada à composição com uma das partes desconhecida. Quanto à terceira, trata-se de uma situação-problema de estrutura multiplicativa que, observando o Esquema do Campo Conceitual Multiplicativo elaborado por Magina, Santos e Merlini (2014), é possível identificar no exemplo uma relação ternária na classe de combinatória.

Ainda na mesma categoria, no que diz respeito à Aritmética, que é o grande foco do início da escolaridade, confirmando o que Lins e Gimenez (1997) fazem referência quando abordam o predomínio da Aritmética nos currículos dos Anos Iniciais. Fica evidente, por meio dos dados coletados, que um grande percentual de professoras possui seu repertório voltado para a aritmética.

Ao analisar a categoria "C3 - Pensamento algébrico com intervenção", é necessário evidenciar que criamos tal categoria em uma referência à produção de texto em que as professoras apresentam aproximações do discurso algébrico, contudo, para que se caracterize uma atividade algébrica, é preciso a realização de intervenções específicas. Com a intervenção da professora, os alunos poderão interpretar a situação-problema, levando-os ao desenvolvimento do pensamento algébrico.

Quadro 8 - Exemplo de textos relacionados a C3

\begin{tabular}{|l|l|}
\hline $\begin{array}{l}\text { 1.Temos: } 3 \text { bolas vermelhas, } 4 \text { bolas verdes, } 2 \text { bolas azuis, } 5 \text { bolas } \\
\text { brancas. Como podes organizar a ordem dessas bolas? Observe que } \\
\text { precisa ter uma sequência. }\end{array}$ & Com intervenção \\
\hline $\begin{array}{l}\text { 2. César e João fazem coleção de carrinhos. César possui } 10 \text { carros e } \\
\text { João } 6 \text { carros. Desenhe quantos carrinhos cada um tem e quanto é } \\
\text { necessário para que os dois tenham a mesma quantidade. }\end{array}$ & Com intervenção \\
\hline
\end{tabular}

Fonte: Dados da pesquisa. 
Trouxemos duas situações-problema para ilustrar os textos referentes à categoria "C3, Pensamento Algébrico com intervenção" e apresentamos sugestões para serem desenvolvidas pelas professoras com seus estudantes. $\mathrm{Na}$ primeira, uma possível intervenção poderia estar atrelada a uma sequência crescente, acrescentando alguns questionamentos, como por exemplo: Como seria possível organizar essas bolas, na ordem crescente de quantidade? Qual seria a cor do primeiro grupo da sequência? E a cor do último grupo? Em seguida, o docente poderia questionar ainda: como ficaria a sequência numérica?; ou, como ficaria a sequência de cores?

$\mathrm{Na}$ segunda situação-problema, a proposta de intervenção seguiria a ideia da equivalência. Para tanto, o docente poderia trabalhar fixando, no exemplo supracitado, a quantidade de carrinhos de César e variar a quantidade de carrinhos de João, solicitando que os estudantes completassem as expressões matemáticas. Por exemplo:

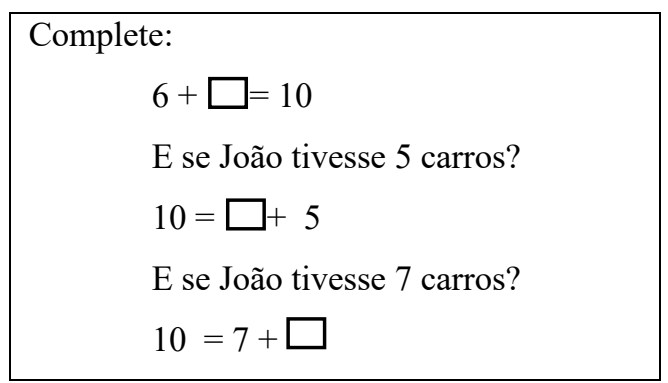

O propósito dessa intervenção também está na alteração do lugar do sinal de igual, para que o estudante desmistifique que depois da igualdade sempre será apresentado um resultado numérico.

Fazendo um diálogo com a análise de Lins e Gimenez (1997), a álgebra não é apenas calcular com letras tampouco trocar o número pela letra. Talvez essa seja uma impossibilidade para o docente, em particular os da educação infantil e os dos Anos Iniciais, ao trabalhar com a Álgebra. A esse respeito, é importante destacar que o pensamento algébrico é apresentado como um eixo estruturante nos elementos conceituais e metodológicos para a definição dos direitos de aprendizagem e desenvolvimento do ciclo de alfabetização (BRASIL, 2012), com o propósito de que os estudantes, a partir de diferentes contextos, possam compreender, reconhecer e produzir padrões, estabelecer critérios para agrupar, classificar e ordenar objetos. 
Os textos da categoria C4 são os denominados como sendo não legitimados. Nessa categoria há três tipos de textos que não são tidos como legítimos: inconsistente, incompleto e inapropriado para a Educação Infantil.

\begin{tabular}{|l|r|}
\hline \multicolumn{2}{|c|}{ Quadro 9 - Exemplo de textos relacionados a C4 } \\
\hline 1. & $\begin{array}{c}\text { Texto não legitimado } \\
\text { (inconsistente) }\end{array}$ \\
\hline $\begin{array}{l}\text { 2. Quantas vezes o lápis pode aparecer nas } \\
\text { trocas de combinações com a bolas de papel } \\
\text { e a borracha? }\end{array}$ & Texto não legitimado \\
(incompleto)
\end{tabular}

No Quadro 9, apresentamos três textos que representam a classificação C4. A primeira situação apresenta inconsistência, por não ser possível compreender o que precisava ser feito para chegarmos à sua resolução. Na segunda situação-problema, a categoria volta a ser aplicada por considerar tal situação incompleta por falta de informações para que pudéssemos compreendê-la. Na terceira, temos uma situação que pode ser considerada como a vertente de equivalência, porém não está apropriada para a educação infantil.

\section{Considerações finais}

O propósito desta pesquisa foi analisar que textos do discurso da álgebra os professores da educação infantil reconhecem antes de iniciarem uma formação em Early Algebra, ao elaborarem situações-problema para seus alunos.

Para o desenvolvimento da pesquisa, foi necessário analisar alguns documentos oficiais e artigos que foram publicados relacionados com o tema proposto. Os documentos 
curriculares oficiais mostram que deve ser garantido às crianças práticas de ensino com o intuito de oferecer elementos que ampliem o discurso algébrico, para que não ocorra distanciamentos entre álgebra e aritmética.

Para Lins e Gimenez (1997), quando os alunos têm a possibilidade de aprender a pensar algebricamente e produzir significados para os termos, desde o início da escolaridade e de modo simultâneo com a aritmética, oferecemos às crianças a oportunidade de ampliar o discurso algébrico gradativamente.

$\mathrm{Na}$ análise das publicações científicas envolvendo textos do discurso da álgebra, esclarecemos a importância do desenvolvimento desse discurso ocorrer de forma simultânea ao discurso algébrico. Para isso, faz se necessário desenvolver atividades que contribuam para ampliação desses conhecimentos de forma simultânea.

Os resultados obtidos na análise dos textos elaborados pelos professores da educação infantil confirmam o que os pesquisadores da Educação Matemática evidenciam em suas publicações, quando relatam que a Aritmética é desenvolvida como se fosse pré-requisito para a introdução da Álgebra nos Anos Finais do Ensino Fundamental, como podemos observar nos resultados obtidos, os quais demostram que o discurso algébrico ainda aparece timidamente entre os textos elaborados e que apesar de documentos e estudos sobre o discurso algébrico, ainda prevalece o discurso aritmético na Educação Infantil.

Com isso percebemos que algumas professoras, mesmo de maneira implícita, trazem elementos do pensamento algébrico para as situações-problema que elaboram, evidenciando assim a necessidade de aproximação do discurso algébrico, ou seja, de aproximação do texto legítimo. Esses resultados nos mostram a necessidade de formações de professores que atuem nos Anos Iniciais, incluindo a Educação Infantil.

Tendo em vista que nossa pesquisa é um recorte de um projeto e que a formação de professores está em andamento, notamos a necessidade de pesquisas futuras dando continuidade a estudos referentes à formação. Além disso, também é possível apontar a necessidade crescente da realização de estudos referentes à análise da produção de textos algébricos com estudantes da educação infantil.

\section{Referências}

ALVES-MAZZOTTI, A. J.; GEWAMDSZNADJDER, F. O método nas ciências naturais e sociais: pesquisa quantitativa e qualitativa. 2. ed. São Paulo: Pioneira, 2002. 
ARCAVI, A. El desarrollo y el uso del sentido de los símbolos. In: VALE, I.; PIMENTEL, T.; BARBOSA, A.; FONSECA, L.; SANTOS, L.; CANAVARRO, P. (Orgs.). Números e Álgebra na aprendizagem da Matemática e na formação de professores. Lisboa: SEMSPCE, 2006.

BERNSTEIN, B. Pedagogy, symbolic control and identity: theory research Critique. Revised Edition. London: Taylor and Francis, 2000.

BERNSTEIN, B. Class, codes and Control, Vol. IV: The structuring of pedagogic discourse. Londres: Routledge, 2003.

BLANTON, Neusa Cristina Vicente. Algebra and the Elementary Classroom:

Transforming Thinking, Transforming Practice. Portsmouth, NA: Heinemann, 2008.

BLANTON, M.; KAPUT, J. Characterizing a classroom practice that promotes algebraic reasoning. Journal for Research in Mathematics Education, EUA, v. 36, n. 5, p. 412-446, 2005.

BRANCO, N. C. V. O Estudo de Padrões e Regularidades no Desenvolvimento do Pensamento Algébrico. 2008. Dissertação (Mestrado) - Faculdade de Ciências, Universidade de Lisboa, Lisboa, 2008, p. 17-19.

BRASIL. Secretaria de Educação Fundamental. Parâmetros Curriculares Nacionais (1 $\mathbf{1}^{\mathrm{a}} \mathbf{4}^{\mathrm{a}}$ série): Matemática. Brasília: MEC/SEF, 1997.

BRASIL. Ministério da Educação e do Desporto. Referencial curricular nacional para a educação infantil. Brasília: MEC/SEF, 1998a.

BRASIL. Secretaria de Educação Fundamental. Parâmetros Curriculares Nacionais: Matemática. Brasília: MEC/SEF,1998b.

BRASIL. Ministério da Educação. Secretaria de Educação Básica. Diretoria de Currículos e Educação Integral - DICEI. Coordenação Geral do Ensino Fundamental - COEF. Elementos conceituais e metodológicos para definição dos direitos de aprendizagem e desenvolvimento do ciclo básico de alfabetização $\left(1^{\circ}, 2^{\circ}\right.$ e $3^{\circ}$ anos $)$ do ensino fundamental. Brasília, DF: MEC, 2012.

BRASIL. Ministério da Educação. Base Nacional Comum Curricular. 2017. Disponível em $<$ http://basenacionalcomum.mec.gov.br/imagens/BNCCpublicacao.pdf $>$. Acesso em: 02 set. 2019

CANAVARO, A. P. O pensamento algébrico na aprendizagem da matemática nos primeiros anos. Quadrante, Portugal, v. XVI, n. 2, 2007.

CARRAHER, D. W.; SCHLIEMANN, A. D. O lugar da álgebra no Ensino Fundamental. In: MARTINS, E.; LAUTERT, S. (Org.). Diálogos sobre o ensino, aprendizagem e a formação 
de professores: Contribuições da Psicologia da Educação Matemática. Rio de Janeiro: Autografia 2016.

CARRAHER, D. W.; SCHLIEMANN, A. D.; SCHWARTZ, J. Early algebra is not the same as algebra early. In: KAPUT, J.; CARRAHER, D.; BLANTON, M. (orgs.). Algebra in the Early Grades. Mahwah, NJ: Erlbaum, 2008. pp. 235-272.

CYRINO, M. C. C. T.; OLIVEIRA, H. M. Pensamento Algébrico ao longo do Ensino Básico em Portugal. Boletim de Educação Matemática, v. 24, n. 38, pp. 97-126, abril, 2011.

FALCÃO, J. T. R. Alfabetização Algébrica nas séries iniciais. Como começar? Boletim GEPEM, no 42 - fev. / jul. 2003.

KATZ, V. J. Algebra: Gateway to a Technological Future. In: Mathematical Association of America, 2007. Disponível em: http://www.maa.org/algebra- report/Algebra-GatewayTech.Future.pdf. Acesso em: 07 fev. 2008.

KIERAN, C. Algebraic thinking in the early grades: what is it? Mathematics Educator, Georgia, v. 8, n. 1, p. 139-151, 2004.

LINS, R. C. A framework for understanding what algebraic thinking is. 1992. Tese (Doctor of Philosophy) - School of Education, University of Nothingam, Nothingam, UK: 1992.

LINS, R. C.; GIMENEZ, J. Perspectivas em aritmética e álgebra para o século XXI. Campinas, SP: Papirus, 1997.

LINS, R.; KAPUT, J. J. The early development of algebraic reasoning: The current state of the field. In CHICK, H.; STACY, K. (Eds.), The Future of the Teaching and Learning of Algebra: The 12th ICMI Study. London: Kluwer, 2004.

LUNA, A. V. A. A modelagem na formação continuada e a recontextualização pedagógica desse ambiente em salas de aula. 2012. Tese (Doutorado) - Programa de PósGraduação em Ensino, Filosofia e História das Ciências, Universidade Federal da Bahia, Salvador, 2012.

LUNA, A.V. A.; SOUZA, C. C. C. F. Discussões sobre o ensino de álgebra nos anos iniciais do Ensino Fundamental. Educ. Matem. Pesq., São Paulo, v. 15, Número Especial, p. 817$835,2013$.

LUNA, A. V. A.; SOUZA, E. G.; BORTOLOTI, R. M. Um zoom nas produções discursivas em tarefas de early algebra de crianças dos anos iniciais do ensino fundamental. Revista Espaço Plural [online]. Paraná, v. 17, n. 36, 2017.

LUNA, A.V.A.; SOUZA, E. G.; SOUZA, C.C.C.F. Caminhos discursivos multimodais na aprendizagem da álgebra no primeiro ano do Ensino Fundamental. In: BORBA, R.; 
GUIMARÃES, G. (org.) Pesquisa e atividades para o aprendizado matemático na educação infantil e nos anos iniciais do ensino fundamental [livro eletrônico]. Brasília: Sociedade Brasileira de Educação Matemática - SBEM, 2015.

MAGINA, S. M. P.; SANTOS, A.; Vera Lucia Merlini. O raciocínio de estudantes do Ensino Fundamental na resolução de situações das estruturas multiplicativas. Ciênc. Educ., Bauru, v. 20, n. 2, p. 517-533, 2014.

NATIONAL COUNCIL FOR TEACHER OF MATHEMAIS/ NCTM. Princípios e Normas para a Matemática Escolar. Trabalho original publicado em 2000. Tradução da Associação de Professores de Matemática (APM). Lisboa: Associação de Professores de Matemática e Instituto de Inovação Educacional, 2007.

OLIVEIRA, C. F. S. Formação continuada de professores e a Early Algebra: uma intervenção híbrida. 2018. Dissertação (Mestrado) - Universidade Estadual de Santa CruzUESC, Bahia, 2018.

PONTE, J. P.; BRANCO, N.; MATOS, A. Álgebra no ensino básico. Lisboa: DGIDC, 2009.

RIBEIRO, E. S. Um estudo sobre o símbolo, com base na semiótica de Peirce. Estudos Semióticos, São Paulo, v. 6, n. 1, p. 46-53, 2010.

SANTANA, E. R. Estruturas Aditivas: o suporte didático influencia a aprendizagem do estudante? 2012. Tese (Doutorado em Educação Matemática) - PUC, São Paulo, 2012.

THOMPSON, F. M. O ensino de álgebra para a criança mais nova. In: COXFORD, A. F.; SHULTE, A. P. (Org.). As ideias da álgebra. (Hygino H. Domingues, trad.). São Paulo: Atual, 1995, p. 79-103.

VALE, I.; PIMENTEL, T. O pensamento algébrico e a descoberta de padrões na formação de professores. Da Investigação às Práticas, v. 3, n. 2, p. 98-124, 2013.

VALE, I.; PIMENTEL, T.; BARBOSA, A.; BORRALHO, A.; CABRITA, I.; FONSECA, L. Padrões em matemática: uma proposta didática do novo programa para o ensino básico.

Lisboa: Texto Editores, 2011. 